\title{
Dynamics of Selected Trace Minerals during Estrus Induction in Anestrus Sahiwal Cattle
}

\author{
Harpreet Singh $^{1 *}$, Sumit Singhal ${ }^{2}$, J.B. Phogat ${ }^{4}$, M.H. Jan ${ }^{3}$, Narinder Singh ${ }^{2}$ and Prahlad Singh ${ }^{2}$ \\ ${ }^{1}$ Regional Centre, ${ }^{4}$ Department of Veterinary Gynaecology and Obstetrics, LUVAS, Karnal, Haryana, INDIA \\ ${ }^{2}$ Department of Veterinary Gynaecology and Obstetrics, GADVASU, Ludhiana, INDIA \\ ${ }^{3}$ ICAR-Central Institute for Research on Buffaloes, Subcampus Bir Dosanjh, Nabha, INDIA \\ "Corresponding author: H Singh; E-mail: hsinghvet@gmail.com
}

Received: 22 Aug., 2019

Revised: 22 Oct., 2019

Accepted: 16 Nov., 2019

\begin{abstract}
The present study evaluated the effect of circulatory trace mineral profiles on fertility response during estrus induction by progesterone based therapy in acyclic Sahiwal cattle. Sahiwal cows and post-pubertal heifers $(\mathrm{n}=25$ each) with true anestrus condition (acyclicity confirmed ultrasonographically) were subjected to CIDR-based protocol (intravaginal CIDR application for 7 days, $500 \mathrm{IU}$ eCG at CIDR removal, followed by estrus observation and AI). In heifers, additionally an injection of 5.0 mg estradiol valerate at CIDR insertion was given. Blood samples on days 0 (before CIDR application), 3, 5, 7 and 9 were collected. Almost similar estrus induction ( $68 \%$ vs. $64 \%)$ and subsequent conception rates $(41.2 \%$ vs. $50 \%)$ during the first induced estrus were recorded in cows and heifers, respectively. During the course of treatment, significant $(\mathrm{P}<0.05)$ variation in plasma copper and zinc concentrations was recorded both in cows and heifers. Contrarily, manganese concentrations varied significantly $(\mathrm{P}<0.05)$ in cows only. However, iron profiles remained uniform during the course of treatment. Significantly $(\mathrm{P}<0.05)$ higher pre-treatment plasma concentrations of copper, zinc and manganese was recorded in those cows and heifers in which estrus was induced, compared to those in which estrus induction failed to occur. No significant difference $(\mathrm{P}>0.05)$ was recorded for iron concentration vis-à-vis estrus induction response. Hence, it is indicated that circulatory copper, zinc and manganese profiles influence the reproductives energy in acyclic animals and their suboptimal profiles may reduce the efficacy of estrus induction protocols in Sahiwal cattle.
\end{abstract}

Keywords: Anestrus, Estrus induction, Sahiwal, Trace minerals

Reproductive rates in Bos indicus are generally lower than Bos taurus mainly due to delayed puberty and prolonged postpartum anestrus (Nascimento et al., 2016). Incidence of true postpartum anestrus varying from $11 \%$ to $38 \%$ in exotic (Peter et al., 2009) to as high as $53.15 \%$ in Indian cattle breeds (Kumar et al., 2014) was recorded. Sahiwal is the best milch breed of indigenous cattle, with reported anoestrus incidence of up to $42.30 \%$ in cows and $64.66 \%$ in heifers in India (Kumar et al., 2014).

Reproductive efficacy of farm animals largely depends on their nutritional status particularly of micronutrients, which are often sub-optimal in developing tropical countries (McGrath et al., 2018). Hence, marginal mineral deficiency, particularly of macro or micro elements is likely to occur in cattle without manifestation of specific symptoms (Balamurugan et al., 2017). Several trace elements act as cofactors with important roles in hormone and other biochemical processes associated with reproduction. Deficiency of trace elements is generally said to affect reproduction in ruminants. In $\geq 70 \%$ of postpartum cows, first spontaneous ovulation is usually followed by abnormal estrus cycle ( $\sim 10$ days) which provides progesterone exposure for a short period before occurrence of first estrus cycle with normal ovulation (Crowe, 2008). Hence, short term progesterone therapy

How to cite this article: Singh, H., Singhal, S., Phogat, J.B., Jan, M.H. Singh, N. and Singh, P. (2019). Dynamics of selected trace minerals during estrus induction in anestrus Sahiwal cattle. J. Anim. Res., 9(6): 843-848. 
in postpartum acyclic cattle mimics this short cycle and aids to induce cyclicity in a substantial proportion (Day, 2002). Satisfactory estrus induction and pregnancy rates following progesterone therapy have been reported in acyclic Sahiwal cattle (Singh et al., 2006). The effect of trace mineral profiles on efficacy of estrus induction protocols and conversely, behavior of mineral profiles during induction of cyclicity has not been well documented. Hence, present experiment evaluated such dynamics of the plasma Copper $(\mathrm{Cu})$, Zinc $(\mathrm{Zn})$, Manganese $(\mathrm{Mn})$ and Iron $(\mathrm{Fe})$ profiles in acyclic Sahiwal postpartum cows and postpubertal heifers.

\section{MATERIALS AND METHODS}

\section{Experimental animals and protocols}

Healthy Sahiwal cows $\left(2^{\text {nd }}\right.$ to $4^{\text {th }}$ parity, body condition score $=2.5-4$ ) with normal parturition and normal genitalia were subjected to gynecological examination at every 15 days interval up to three months postpartum.

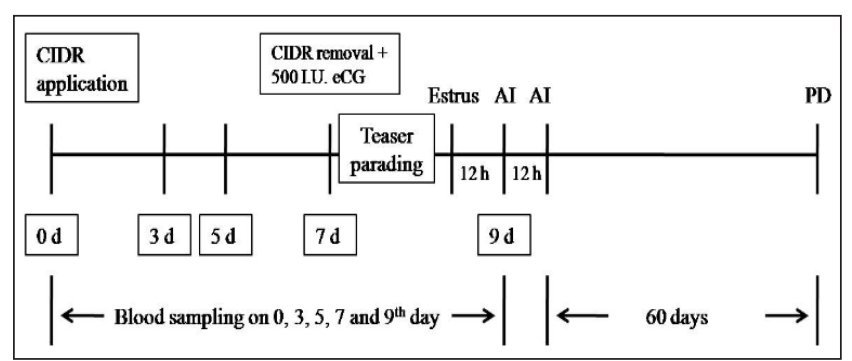

Protocol: 1

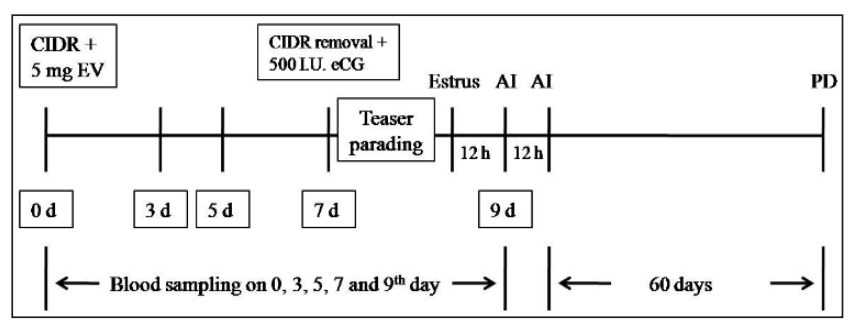

Protocol: 2

Fig. 1: CIDR-based estrus induction protocols for Sahiwal cows (Protocol 1) and heifers (Protocol 2)

$E V$ (estradiol valerate), eCG (equine chorionic gonadotropin), AI (Artificial Insemination), $d$ (days), h (Hours), PD (Pregnancy Diagnosis)
Thereafter, a total of 25 cows from these confirmed for acyclicity (trans-rectal ultrasonography, twice at 10 days interval) were selected. Likewise, healthy post-pubertal Sahiwal heifers ( $\mathrm{n}=25, \geq 2 \frac{1}{2}$ years age, $250-350 \mathrm{~kg}$ average body weight) with anestrus condition (since attainment of sexual maturity) were selected. These animals were enrolled for induction of cyclicity using seven day intravaginal progesterone therapy (Fig. 1: protocol 1 in acyclic cows, $n=25$; modified protocol 2 in heifers, $n=$ 25).

The selected cows were identified with ear tags and not isolated from the herd. The controlled internal drug release device (CIDR, containing $1.38 \mathrm{~g}$ of natural progesterone, Inter AG. Hamilton, New Zealand) was applied as per standard procedure. Cows were observed for behavioral estrus aided by parading a teaser bull daily at 0600 and 1800 hours. Artificial insemination was done with good quality frozen semen. Pregnancy diagnosis at 60 days post-insemination was performed by trans-rectal ultrasonography.

\section{Plasma trace mineral profiles}

The concentration of trace minerals $(\mathrm{Cu}, \mathrm{Zn}, \mathrm{Mn}$ and $\mathrm{Fe}$ ) in Jugular blood plasma samples was estimated by a double beam atomic absorption spectrophotometer using optimum instrumental settings and standard procedure. Standard curves were obtained by using different standards of known concentrations for each element. Each assay was checked intermittently by using different standards of that element.

\section{Statistical Analysis}

Analysis of the experimental data was carried out using analysis of variance (ANOVA) and Student's t-test as described by Snedecor and Cochran (1994).

\section{RESULTS AND DISCUSSION}

Infertility in livestock arising from trace minerals deficiency is believed to be associated with enzymatic and endocrine dysfunctions along the hypothalamo-gonadal axis (Princewill et al., 2015). Our results indicated that plasma concentrations of copper, zinc and manganese influence the outcome of estrus induction protocols. In the 
present experiment, the estrus induction and subsequent conception rates during the first induced estrus in postpartum cows were $68 \%$ and $41.2 \%$, respectively. The corresponding values in post-pubertal heifers were $64 \%$ and $50 \%$, respectively (Fig. 2).

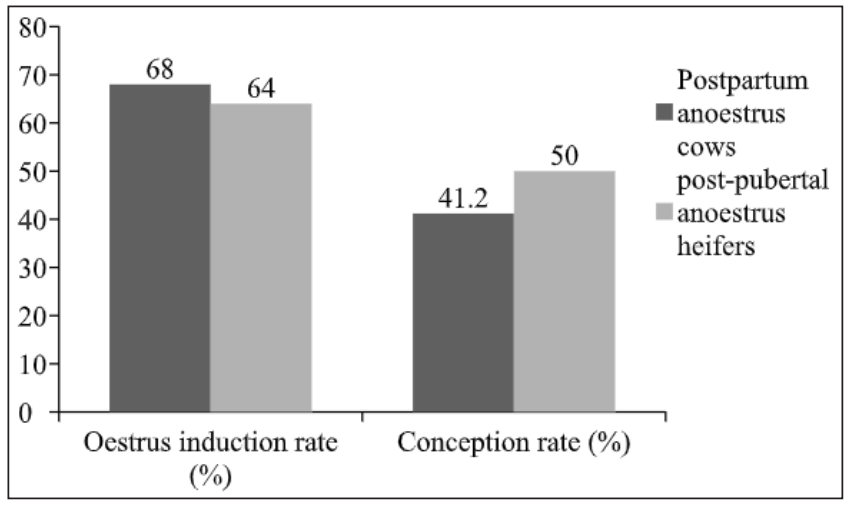

Fig. 2: Fertility response of CIDR based protocols in anestrus Sahiwal cows and heifers

The plasma concentrations of $\mathrm{Cu}, \mathrm{Zn}, \mathrm{Mn}$ and $\mathrm{Fe}$ in treated cows and heifers are presented in Fig. 3 and 4. Significant variation $(\mathrm{P}<0.05)$ in plasma concentrations of $\mathrm{Cu}$ and $\mathrm{Zn}$ was observed both in cows and heifers during the course of CIDR application. There was an increasing trend of $\mathrm{Cu}$ concentrations in cows as well as heifers. Contrarily, the manganese concentrations varied significantly $(\mathrm{P}<0.05)$ only in cows and not in heifers.

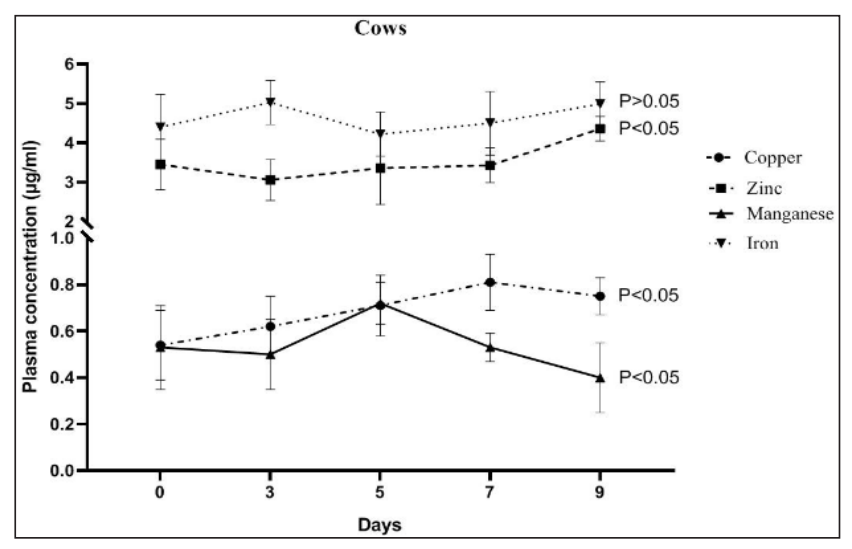

Fig. 3: Plasma concentrations $(\mu \mathrm{g} / \mathrm{ml})$ of trace minerals (Mean \pm SE) during the course of estrus induction in postpartum Sahiwal cows

However, iron concentrations remained uniform during the course of treatment both in cows and heifers. The lower
$\mathrm{Cu}$ concentration in anestrus animals has been attributed to prevailing lower estrogen profile (Rajkumar et al., 2006). Likewise, increased plasma concentration of $\mathrm{Cu}$ (with no effect on $\mathrm{Zn}$ ) was reported following administration of estrogen (Sato and Henkin, 1973). Hence, the variation in mineral concentrations recorded in present experiment may perhaps be due to endocrine changes following activation of reproductive axis during estrus induction. However, further investigations are warranted to establish such changes in mineral profiles.

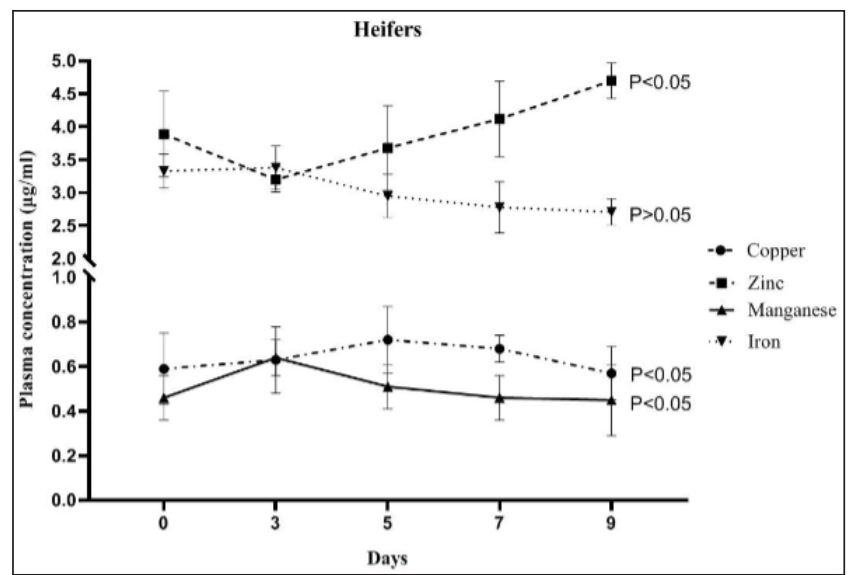

Fig. 4: Plasma concentrations $(\mu \mathrm{g} / \mathrm{ml})$ of trace minerals (Mean \pm SE) during the course of estrus induction in post pubertal Sahiwal heifers

Pre-treatment concentrations of trace minerals were also compared with respect to the outcome of treatment (estrus induced vs. not induced). No significant difference $(\mathrm{P}>0.05)$ was recorded for iron concentration vis-à-vis estrus induction response (Fig. 5 and 6). In contrast, the mean pre-treatment concentrations of copper, zinc and manganese were significantly $(\mathrm{P}<0.05)$ higher both in cows and heifers in which estrus induction was successful as compared to those in which estrus induction failed to occur. This indicated that the success of estrus induction protocols also depends on circulatory trace mineral status especially copper, zinc and manganese. The role of trace minerals in maintaining optimum fertility has been demonstrated in various studies through its involvement in GnRH, FSH, LH and estrogen activity (Michaluk and Kochman, 2007). Suboptimal ovarian activity, delayed or depressed estrus (Mudgal et al., 2018), and delayed puberty were reported in cattle and buffaloes grazing on pastures low in $\mathrm{Cu}$ (Kumar et al., 2003). On the contrary, 
Das et al. (2009) recorded no significant difference in serum copper profiles among crossbred cattle with various ovulatory disturbances (delayed ovulation, anovulation) and normal ovulation. Copper is essential for the activity of superoxide dismutase enzyme, the deficiency of which has been associated with defects in ovarian folliculogenesis (Lei et al., 2015).

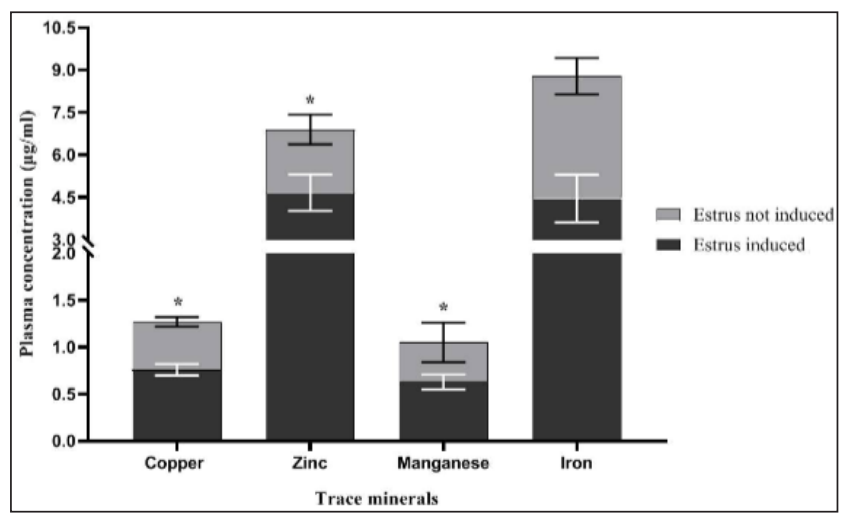

Fig. 5: Pre-treatment plasma concentration $(\mu \mathrm{g} / \mathrm{ml})$ of trace minerals (Mean $\pm \mathrm{SE}$ ) in relation to induction of estrus in treated cows.

$*(P<0.05)$ indicate significant difference between responsive versus unresponsive animals.

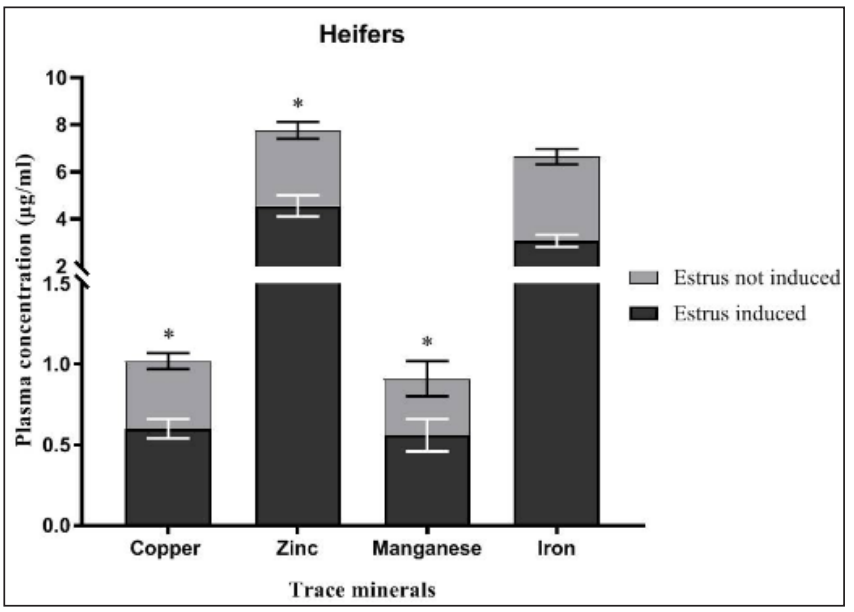

Fig. 6: Pre-treatment plasma concentration $(\mu \mathrm{g} / \mathrm{ml})$ of trace minerals (Mean $\pm \mathrm{SE}$ ) in relation to induction of estrus in treated heifers

$*(P<0.05)$ indicate significant difference between responsive versus unresponsive animals

Copper is known to be an extremely potent releaser of $\mathrm{GnRH}$. Copper catalyzes first step of amidation reaction for activation of active GnRH peptide from the pro-hormone (Prigge et al., 2000) and also complexes with GnRH to modulate intracellular signaling in the gonadotrope cells of the anterior pituitary (Michaluk and Kochman, 2007).

Zinc (Zn) also plays an essential component of enzymes in different biochemical pathways and thus plays a pivotal role in reproduction. Delayed puberty in heifers (Ahmed et al., 2002), lower conception rates and failure of implantation in $\mathrm{Zn}$ deficient cows have been recorded (Verma and Kumar, 2018), while its supplementation increased calving rates in heifers (Patel et al., 2017). Zinc deficiency leads to suppression of hypothalamo-pituitarygonadal axis and is directly involved in activity of steroid receptors owing to its presence in the form of ' $\mathrm{Zn}$ fingers' (Kluska et al., 2018).

Our study recorded that manganese concentration also influenced the outcome of estrus induction protocols, and the failure of estrus induction may be due to marginal manganese deficient state. Poor follicular development with delayed ovulation, reduced intensity of estrus and reduced conception rates has been associated with Mn deficiency (Kumar et al., 2011). Manganese supplementation has proven to be effective in shortening the postpartum anestrus period and increasing conception rates in dairy animals (Ullah et al., 2010). The lower serum Mn concentration was reported in delayed ovulating and an ovulating compared to the normal ovulating heifers (Das et al., 2009). Although the precise mechanism pertaining to the involvement of manganese in reproduction is unknown, its deficiency alters the synthesis of estrogen and progesterone in the females, possibly through the inhibition of cholesterol and cholesterol precursor synthesis (Pradhan and Nakagoshi, 2008).

Iron concentrations in the present experiment were within the physiological range. There was no significant variation during the course of treatment and also between responsive versus unresponsive animals, indicating perhaps an optimal supply of this micronutrient. In contrast, Lower level of serum iron plays a significant role in causing failure of conception and embryonic death (Modi et al., 2013). Deficiency of Fe in dairy cows rarely occurs, except in cases of some parasitic and infectious diseases as most of the conventional diets contain sufficient amounts of $\mathrm{Fe}$ (Theil, 2004).

The results indicate that $\mathrm{Cu}, \mathrm{Zn}$ and $\mathrm{Mn}$ exert influence 
on reproductive synergy/performance and their deficiency may influence the outcome of estrus induction protocols in acyclic cattle. Hence it becomes essential to optimize circulatory profiles of trace minerals before induction of cyclicity or synchronization.

\section{REFERENCES}

Ahmed, M.M.M., Fadlalla, I.M.T. and Barri, M.E.S. 2002. A possible association between dietary intake of copper, zinc and phosphate and delayed puberty in heifers in Sudan. Trop. Anim. Health Prod., 34: 75-80.

Balamurugan, B., Ramamoorthy, M., Ravi, J., Keerthana, G., Gopalakrishnan, K.M., Kharayat, S., Chaudhary, G.R. and Rahul, K. 2017. Mineral an important nutrient for efficient reproductive health in dairy cattle. Int. J. Environ. Sci. Technol., 6: 694-701.

Crowe, M.A. 2008. Resumption of ovarian cyclicity in postpartum beef and dairy cows. Reprod. Domest. Anim., 43: 2028.

Das, J.M., Dutta, P., Deka, K.C., Biswas, R.K., Sarmah, B.C. and Dhali, A. 2009. Comparative study on serum macro and micro mineral profiles during oestrus in repeat breeding crossbred cattle with impaired and normal ovulation. Livestock Res. Rural Dev., 21: Article \#72.

Day, M.L. 2002. Application of the CIDR-B to Estrus Synchronization in beef cattle. In: Proc. of the 2002 CHIPS Beef Breeding Management, ICN Conference, Ames, IA, USA. https://agnr.osu.edu/sites/agnr/files/imce/pdfs/Beef/ ApplicationOfTheCIDR.pdf

Kluska, K., Adamczyk, J, and Krężel, A. 2018. Metal binding properties, stability and reactivity of zinc fingers. Coord. Chem. Rev., 367: 18-64.

Kumar, P.R., Singh, S.K., Kharche, S.D., Govindaraju, C.S., Behera, B.K., Shukla, S.N., Kumar, H. and Agarwal, S.K. 2014. Anestrus in cattle and buffalo: Indian perspective. $A d v$. Anim. Vet. Sci., 2: 124-138.

Kumar, S., Das, G.K., Pandel, K.P. and Kumar, D. 2003. Nutrition and reproduction: macro and micro nutrients in relation to fertility and infertility. Indian Vet. Med. J., 27: 1-10.

Kumar, S., Pandey, A.K., Abdul-Razzaque, W.A. and Dwivedi, D.K. 2011. Importance of micro minerals in reproductive performance of livestock. Vet. World, 4: 230-233.

Lei, X.G., Zhu, J.H., Cheng, W.H., Bao, Y., Ho, Y.S., Reddi, A.R., Holmgren, A. and Arnér, E.S. 2015. Paradoxical roles of antioxidant enzymes: basic mechanisms and health implications. Physiol. Rev., 96: 307-364.

McGrath, J., Duval, S.M., Tamassia, L.F.M., Kindermann, M., Stemmler, R.T., de Gouvea, V.N., Acedo, T.S., Immig, I.,
Williams, S.N. and Celi, P. 2018. Nutritional strategies in ruminants: A lifetime approach. Res. Vet. Sci., 116: 28-39.

Michaluk, A. and Kochman, K. 2007. Involvement of copper in female reproduction. Reprod. Biol.,7: 193-205.

Modi, L.C., Suthar, B.N., Chaudhari, C.F., Chaudhari, N.F., Nakhashi, H.C. and Modi, F. 2013. Trace minerals profile of blood serum and estrual mucus in repeat breeder Kankrej cows. Vet. World, 6: 143-146.

Mudgal, V., Gupta, V.K., Srivastava, S. and Ganai, A.A. 2012. Serum Concentrations of Iron, Copper, Zinc, Manganese and Cobalt in anoestrus cattle and buffaloes under farm condition. Int. J. Livest. Res., 2: 150-159.

Nascimento, A.V., Matos, M.C., Seno, L.O., Romero, A.R., Garcia, J.F. and Grisolia, A.B. 2016. Genome wide association study on early puberty in Bos indicus. Genet. Mol. Biol., 15: $1-6$.

Patel, B., Kumar, N., Jain, V., Ajithakumar, H., Kumar, S., Raheja, N., Lathwal, S., Datt, C. and Singh, S. 2017. Zinc supplementation improves reproductive performance of Karan-Fries cattle. Indian J Anim. Rprod., 38: 20-22.

Peter, A.T., Vos, P.L.A.M. and Ambrose, D.J. 2009. Postpartum anestrus in dairy cattle. Theriogenology, 71: 1333-1342.

Pradhan, R. and Nakagoshi, N. 2008. Reproductive Disorders in Cattle due to Nutritional Status. J Int. Develop. Coop., 14: 45-66.

Prigge, S.T., Mains, R.E., Eipper, B.A. and Amzel, L.M. 2000. New insights into copper monooxygenase and peptide amidation: structure, mechanism and function. Cell. Mol. Life. Sci., 57: 1236-1259.

Princewill, O.I., Uchenna, A.E., Charles, O.I. and Uwaezuoke, I.M. 2015. Interactions between Dietary Minerals and Reproduction in farm Animal. Global J. Anim. Sci. Res., 3: 524- 535

Rajkumar, R., Srivastava, S.K., Yadav, M.C., Varshney, V.P., Varshney, J.P. and Kumar, H. 2006. Effect of homeopathic complex on oestrus induction and hormonal profile in anoestrus cows. Homeopathy, 95: 131-135.

Sato, N. and Henkin, R.I. 1973. Pitutary gonadal regulation of copper and zinc metabolism in the female rat. Am. J. Physiol., Cell Physiol., 255: 508-512.

Singh, H., Luthra, R.A., Khar, S.K. and Nanda, T. 2006. Oestrus induction, plasma steroid hormone profiles and fertility response after CIDR and eCG treatment in acyclic sahiwal cows. Asian-Australas. J. Anim. Sci., 19(11): 1566-1573.

Snedecor, G.M. and Cochran, W.G. 1994. Statistical methods. $8^{\text {th }}$ edn. Oxford and IBM Publishing Company. Bombay, India.

Theil, E.C. 2004. Iron, ferritin and nutrition. Annu. Rev. Nutr., 24: 327-343. 
Ullah, N., Anwar, M., Andrabi, S.M.H., Ansari, M.S., Murtaza, S., Ali, Q. and Asif, M. 2010. Effect of mineral supplementation on postpartum ovarian activity in Nili-Ravi buffaloes (Bubalus bubalis). Pak. J. Zool., 43: 195-200.
Verma, A. and Kumar, P. 2018. Important minerals affect the fertility of dairy animals: A review. The Pharma Innov. J., 7(11): 136-138. 